\title{
Analysis of Energy Savings and Visual Comfort Produced by the Proper Use of Windows
}

\author{
I. Acosta, M. A. Campano, and J. F. Molina
}

\begin{abstract}
The aim of this research is to quantify the daylight autonomy and the useful daylight illuminance produced inside a room for different models of windows, and to conduct an analysis of the results obtained. The shape, size and position of the window are variable, as is the reflectance of the inner surfaces of the room. A total of 28 simulations are provided by the lighting simulation program DaySim 3.2. After trials it was concluded that the daylight autonomy is directly proportional to the glass surface in the back of the room, while its influence in the zone near the façade is negligible. However, the energy saving does not depend on the window shape. It is also concluded that the windows in the upper position allow higher luminance at the back of the room than those in centered locations.
\end{abstract}

Index Terms-Daylight autonomy, energy saving, useful daylight illuminance, window.

\section{INTRODUCTION}

Windows are a key element in architecture, as they represent the most basic resource for allowing natural light inside buildings [1]. The proper design of windows also improves thermal comfort and brings about a notable energy saving in artificial lighting [2]-[4].

Daylight factor is the simplest and most common measure to quantify the daylight allowed by a window, as they express the potential illuminance inside a room in the worst possible scenario, under overcast sky conditions when there is less exterior daylight. Moreover, this definition is recognized by the CIE as one of the key metrics in lighting [5]. Since daylight factors are assessed under overcast conditions, the sun's position is not relevant, so the calculation is independent of the location of the room. Therefore, the measurement of daylight factors does not depend on time, window orientation or location of the room.

Nevertheless, it is important to mention other methods for daylight evaluation, such as daylight autonomy [6], developed by Reinhart et al., which is one of many currently existing metrics that consider the dynamic aspects of daylight and is usually applied for annual calculations.

At present, lighting simulation programs allow the calculation of daylight autonomy with greater accuracy than empirical methods [7], [8], making them extremely useful tools in the field of natural lighting.

Furthermore, lighting simulation programs have allowed the development of new methods for calculating daylight

Manuscript received November 11, 2014; revised February 28, 2015 This work was supported in part by the University of Seville.

The authors are with Instituto Universitario de Arquitectura y Ciencias de la Construcción, Universidad de Sevilla, Spain (e-mail: iacosta@us.es). metrics, whose accuracy has been supported by computer simulations. An example of this is the study by Ghisi et al. [9], who developed a calculation method, contrasted with VisualDOE, which determines the ideal window area for maximum efficiency considering the use of natural and artificial lighting. The authors conclude that smaller or wide rooms result in greater energy savings in lighting and the ideal window area tends to be higher in low thermal load orientations. Another notable example can be found in the research of $\mathrm{Li}$ et al. [10], who developed a calculation procedure relying on the daylight coefficient concept and confirming the results using the Radiance program. In this study, the authors create a method based on multiple tables and charts for establishing illuminance.

Lighting simulation programs have been used to establish the design conditions of windows and rooms [11]. A noteworthy example is that of the research by Munoz et al. [12], where the authors analyze different metrics in an office illuminated through windows. This study allows the authors to quantify the loss of performance of windows depending on external obstructions.

\section{OBJECTIVES}

The aim of this research is to quantify the daylight autonomy and the useful daylight illuminance inside a room for different models of windows, conducting an analysis of the results obtained.

Accordingly, this research is based on three main objectives:

1) To represent the quantification of daylight autonomy and useful daylight illuminance in more conventional calculation models, so that it serves as a reference for window design in architecture.

2) To conduct an analysis of the resulting daylight autonomy and obtain criteria for shape, size and position of windows.

3) To determine the energy saving produced by different models of windows.

\section{METHODOLOGY}

\section{A. Model}

The calculation model for the analysis of daylight autonomy is defined as a room $3.00 \mathrm{~m}$ wide by $6.00 \mathrm{~m}$ deep by $3.00 \mathrm{~m}$ high. The ceiling, walls and floor of the room have a thickness of $0.25 \mathrm{~m}$. A window of variable shape, size and position is located in the $3.00 \mathrm{~m}$ wide façade. The double-leaf window has $0.05 \mathrm{~m}$ thick joinery and double glazing which 
produces a solar factor of 0.75 . The reflectance of the inner surfaces of the calculation model is variable, accordingly two basic room models -with light or dark surfaces- are defined. The inner surfaces of the room are diffuse reflectors and the Lambertian reflection of daylight is therefore directly proportional to the cosine of the angle between the observer's line of sight and the surface normal. All variables of the calculation model are shown in Fig. 1.

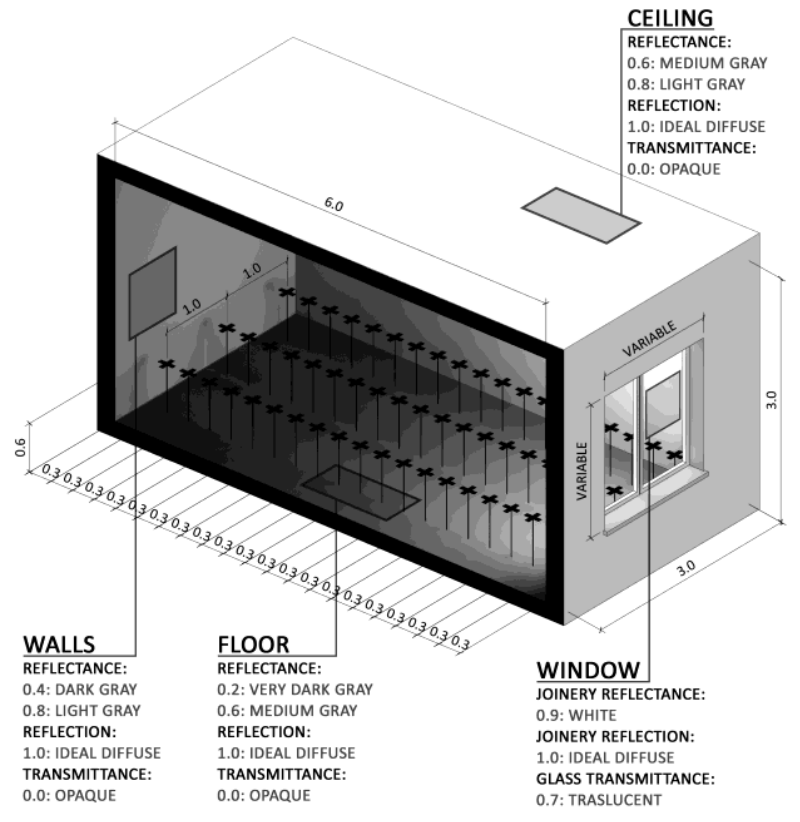

Fig. 1. Calculation model.

The measurement of daylight autonomy is performed on the axis of symmetry of the calculation model and on two equidistant axes at $1.00 \mathrm{~m}$. Therefore, the study points are located on these axes with a spacing of $0.30 \mathrm{~m}$ and a height above ground of $0.60 \mathrm{~m}$.

The calculation model is defined according to the following variables:

Window shape:

$\mathrm{S}: \quad$ Square shape, length/height ratio of $1 \cdot 1$.

$\mathrm{H}$ : Horizontal shape, length/height ratio of $2 \cdot 1$.

$\mathrm{V}$ : Vertical shape, length/height ratio 1.2.

Window size:

10: Window to Façade ratio $10 \%$, equivalent to $0.90 \mathrm{~m}^{2}$.

20: Window to Façade ratio $20 \%$, equivalent to $1.80 \mathrm{~m}^{2}$.

30: Window to Façade ratio $30 \%$, equivalent to $2.70 \mathrm{~m}^{2}$.

40: Window to Façade ratio $40 \%$, equivalent to $3.60 \mathrm{~m}^{2}$.

60: Window to Façade ratio $60 \%$, equivalent to $5.40 \mathrm{~m}^{2}$.

80: Window to Façade ratio $80 \%$, equivalent to $7.20 \mathrm{~m}^{2}$.

Window position:

C: Window in centered position on the façade.

$\mathrm{U}$ : Window in upper position on the façade, with the sill at $1.50 \mathrm{~m}$ above room floor level.

Room reflectance:

B: Bright room: Bright room: Room surfaces with an average reflectance of $75 \%$.

D: Dark room: Bright room: Room surfaces with an average reflectance of $40 \%$.

These variables have been established according to the most common parameters of shape, size and position of the window of a conventional room.

\section{B. Program}

The analysis of the daylight autonomy was carried out using simulation program DaySim 3.2, which calculates luminous distribution using the ray-tracing process. Several studies have confirmed the correct behavior of this calculation program [13], determining their accuracy by applying the CIE test cases [7]. The calculation parameters used in this program are shown in Table I:

\begin{tabular}{|l|l|l|}
\hline \multicolumn{3}{|c}{ TABLE I: CALCULATION PARAMETERS OF DAYSIM 3.2. } \\
\hline Radiance Simulation Parameters & Ambient Bounces & 7 \\
\cline { 2 - 3 } & Ambient Divisions & 1500 \\
\cline { 2 - 3 } & Ambient Super-samples & 100 \\
\cline { 2 - 3 } & Ambient Resolution & 300 \\
\cline { 2 - 3 } & Ambient Accuracy & 0.05 \\
\cline { 2 - 3 } & Limit Reflection & 10 \\
\cline { 2 - 3 } & Specular Threshold & 0.000 \\
\cline { 2 - 3 } & Specular Jitter & 1.000 \\
\cline { 2 - 3 } & Limit Weight & 0.004 \\
\cline { 2 - 3 } & Direct Jitter & 0.000 \\
\cline { 2 - 3 } & Direct Sampling & 0.200 \\
\cline { 2 - 3 } & Direct Relays & 2 \\
\cline { 2 - 3 } & Direct Pretest Density & 512 \\
\hline
\end{tabular}

\section{Sky Conditions}

The weather conditions correspond to the city of London, located at Latitude $51.00^{\circ}$ and Longitude $0.00^{\circ}$. The weather data is obtained from Energy Plus [14], considering the Perez et al. sky model [15], according to the following formulae:

$$
\mathrm{La} / \mathrm{Lz}=(f(\chi) \cdot \varphi(Z)) /(f(Z s) \cdot \varphi(0))
$$

where the variables $\chi, Z s$ and 0 depends on the sky conditions and the position of the Sun and $\mathrm{Z}$ is:

$$
Z=\pi / 2-\gamma
$$

where $\gamma$ is the angle of elevation of the sky element.

\section{Calculation Conditions}

The calculation of daylight autonomy and useful daylight illuminance have been developed considering an occupancy hours from 8:00 am to 5:00 pm, with one break to lunch. The illuminance threshold for the daylight autonomy calculation is 250 lux. The blind control is active, so the users avoid direct sunlight on work plane.

\section{Calculation}

According to the methodology described, the daylight autonomy is measured in the study points represented in Fig. 1. The values obtained show the independence of artificial lighting in the room and therefore the relative energy saving in power consumption. A proper value of daylight autonomy is located between 50 and $100 \%$.

The measurement of the useful daylight illuminance (UDI), shown as columns in Fig. 2, represents the visual comfort inside the room. The higher the UDI value between 100 and 2,000 lux, the better the visual comfort. In addition, the UDI values lower than 100 lux and higher than 2,000 lux are also measured. A proper value of useful daylight illuminance is located between 70 and $100 \%$. 


\section{S.10.C.B}
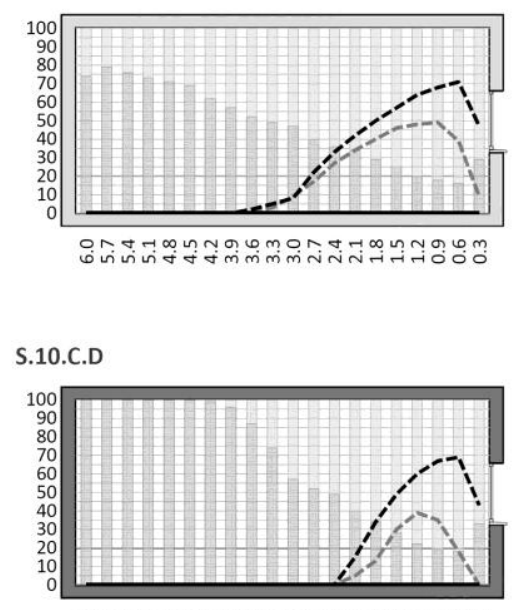

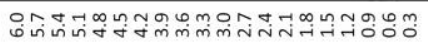
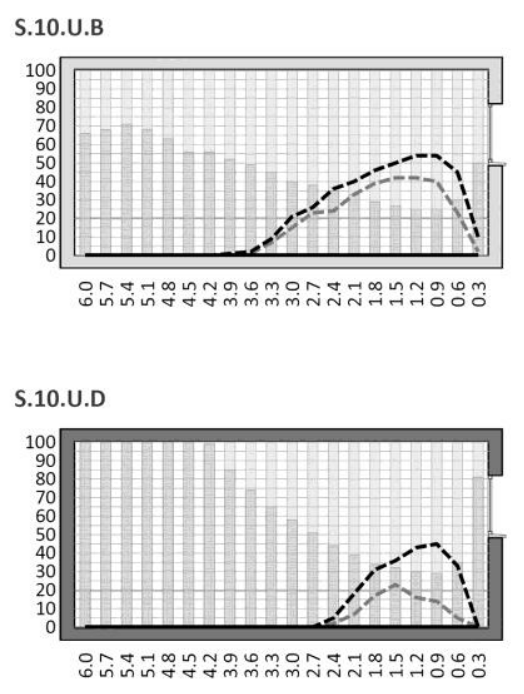

UDI $>2000$
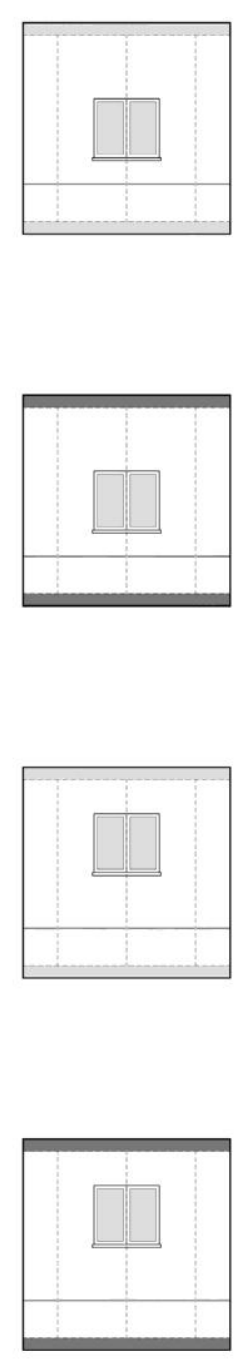

UDI $<100$
S.20.U.B

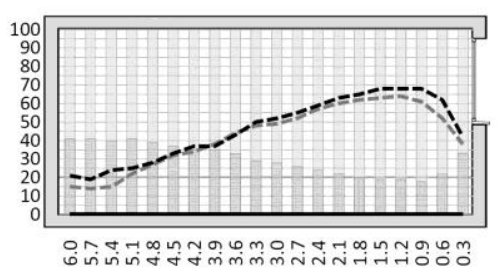

S.20.U.D

S.20.C.B

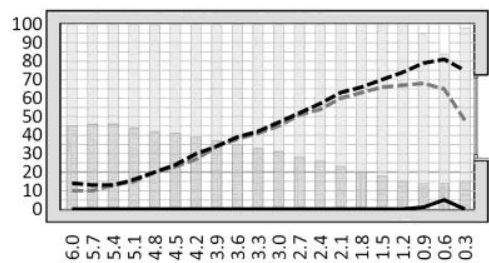

S.20.C.D

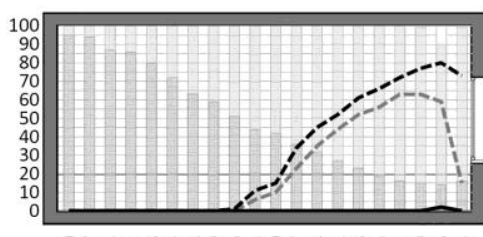

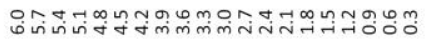
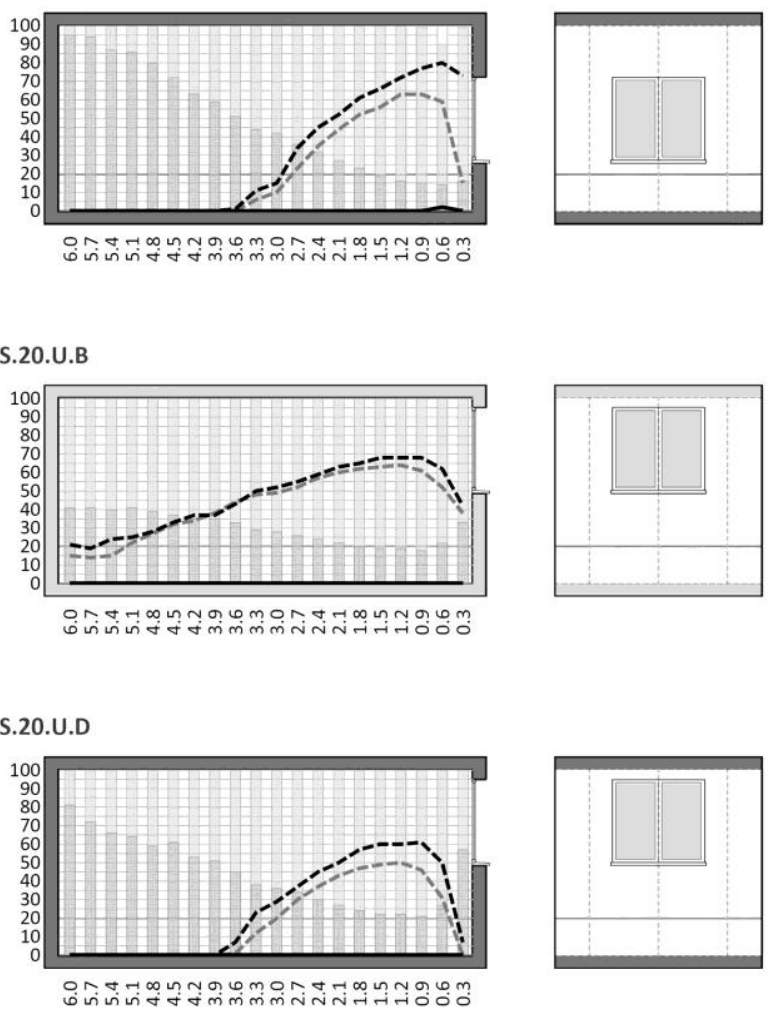

-DAmax

Fig. 2. Daylight autonomy and useful daylight illuminance for rooms with square windows with surface between 10 and $20 \%$ of the façade.

Fig. 2 shows the daylight autonomy and the useful daylight illuminance measured at the study points in rooms with square windows, considering a surface between 10 and $20 \%$ of the façade, under the conditions established in the methodology.

As can be seen in Fig. 2, the rooms with a square window equal to $10 \%$ of the façade do not reach a proper value of daylight autonomy. The back of the room has a completely dependence on artificial lighting. Furthermore, the useful daylight illuminance values only reach a proper value in the zone near the window.

Moreover, in the case of the rooms with a window size equal to $20 \%$ of the façade area, the daylight autonomy reaches a value close to $70 \%$ in the area near the window. The useful daylight illuminance values also get a proper value in the zone between 0 to 2 meters from the façade. However, the values of daylight autonomy and useful daylight illuminance are not enough for the back of the room.

Regarding to the reflectance of surfaces, it is observed that the daylight autonomy reaches a value near $20 \%$ in the back of the room, considering a high reflectance of the inner surfaces. In fact, the average daylight autonomy increases a $35 \%$ in the case of rooms with high reflectance. Therefore, the use of high reflectance surfaces affects noticeable to the energy saving in artificial lighting.

The useful daylight illuminance is also affected by the reflectance of the inner surfaces. As can be seen in models S.20.C.B and S.20.U.B, the UDI values between 100 and 2,000 lux are higher than in those models with low reflectance.

As can be deduced from the comparison of models S.20.C.B and S.20.U.B, the upper position of the window allows higher values of daylight autonomy and useful daylight illuminance in the back of the room.

Fig. 3 shows the daylight autonomy and the useful daylight illuminance measured at the study points in rooms with square windows, considering a surface between 30 and $80 \%$ of the façade, under the conditions established in the methodology.

The square windows in upper position with a surface equal or higher than $30 \%$ of the façade are ignored in the calculation models, as the opening would be outside the surface of the façade.

A total of 16 calculation models with square windows are considered, depending on the window surface, the opening position and the reflectance of the inner surfaces of the room. 
As can be deduced from Fig. 3, the measurement of the daylight autonomy in the study points shows very variable results. As expected, higher daylight autonomy are observed in all cases at the study points closest to the window, gradually descending towards the back of the room.
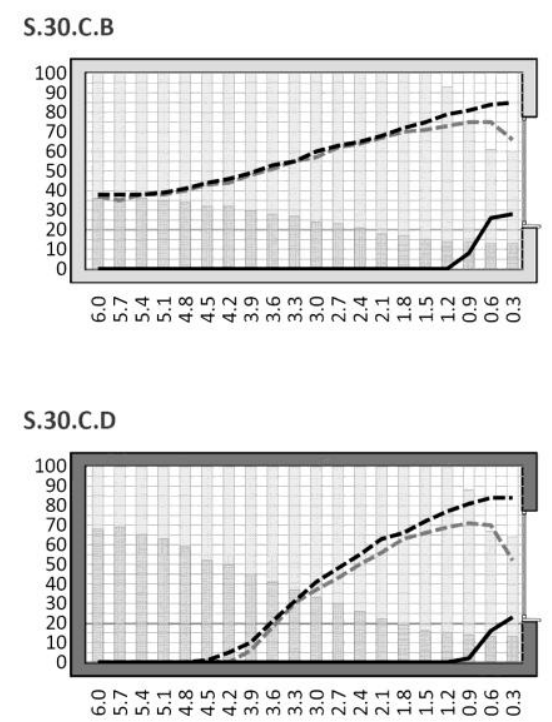

S.60.C.B

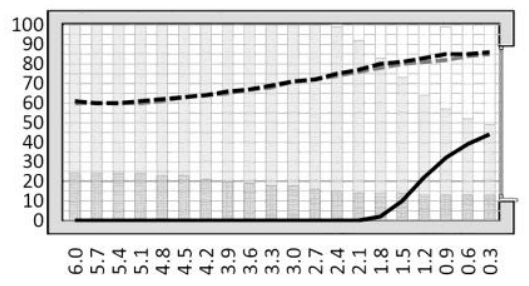

S.60.C.D

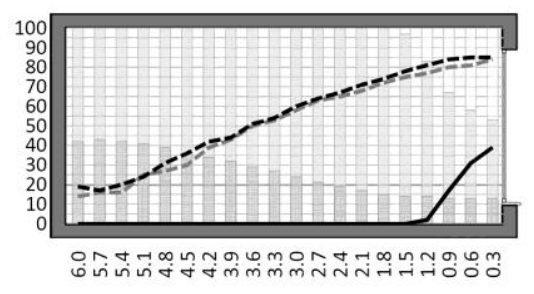

UDI $>2000$
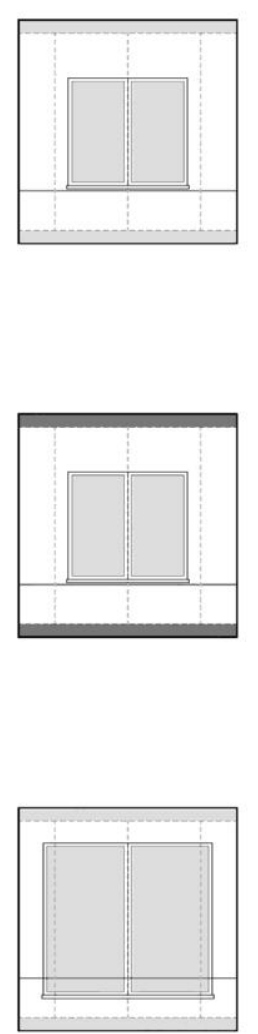

S.80.C.B

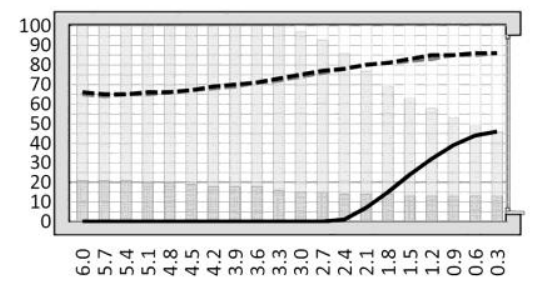

S.80.C.D

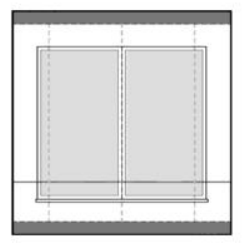

UDI $<100$

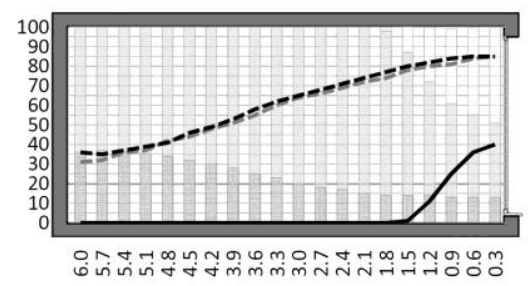

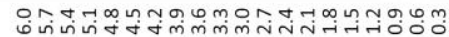

S.40.C.B

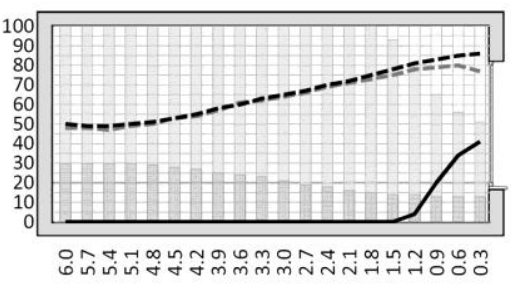

S.40.C.D
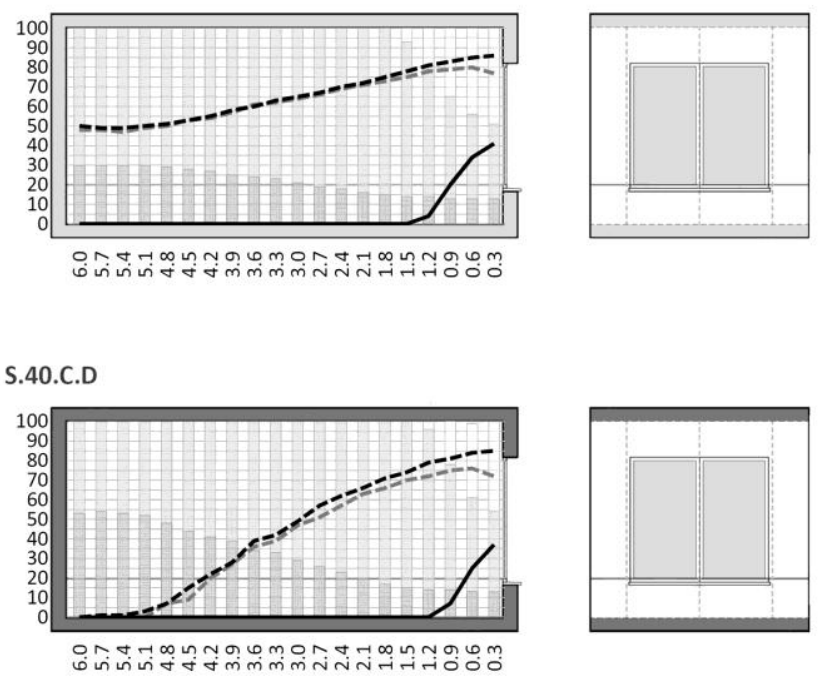
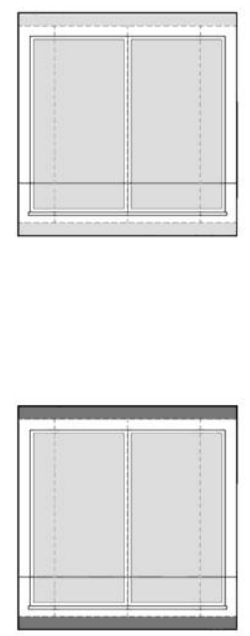

--.CENTER DAYLIGHT AUTONOMY -DAmax

Fig. 3. Daylight autonomy and useful daylight illuminance for rooms with square windows with surface between 30 and $80 \%$ of the façade.

The daylight autonomy observed in the side axis is slightly lower than those measured on the central axis. In any case, this difference diminishes as the end of the room is approached. From this observation it is concluded that the illumination is lower in the back of the room, although it is distributed more evenly.

Obviously, the windows with a greater surface allow higher daylight autonomy. However, as can be deduced from the results obtained, there is no direct proportionality

Fig. 4 shows the daylight autonomy and useful daylight illuminance measured at the study points in rooms with horizontal windows, under the conditions established in the methodology.

The horizontal windows with a surface equal or higher than $30 \%$ of the façade are ignored in the calculation models because according to the height/width ratio of the opening between the glazed area and the daylight autonomy produced, except at the study points near the back of the room.

As can be observed, the bright room with a window surface equal to $30 \%$ of the façade (S.30.C.B) allows a value of daylight autonomy of $70 \%$ in the zone near the window and close to $40 \%$ in the back of the room. In the case of a window equal to $40 \%$ of the façade (S.40.C.B), it can be concluded that the daylight autonomy and the useful daylight illuminance are appropriate for all the study points.

they would be disproportionate to the façade.

A total of 8 calculation models with horizontal windows is considered, depending on the window surface, the opening position and the reflectance of the inner surfaces of the room.

As can be seen in Fig. 4, the daylight autonomy and the useful daylight illuminance measured at the study points of the calculation models with horizontal windows show a 
similar tendency to those of analogous models with square windows: higher daylight autonomy is observed near the window, while lower ones is found at the back of the room.

Furthermore, the daylight autonomy obtained in the central axis with horizontal windows is slightly lower than those produced by square windows of equal area. However, in this study, the difference between the daylight autonomy measured in the central and side axes is smaller than that in the calculation models with a square window, converging at the back of the room. Therefore, it is concluded that horizontal windows produce less illuminance than square
H.10.C.B

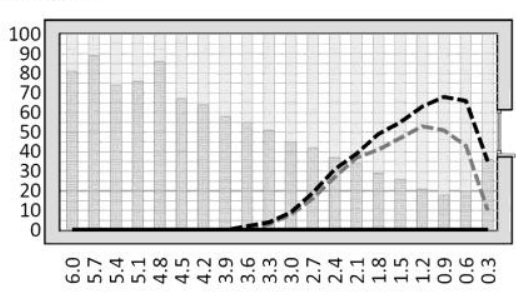

H.10.C.D

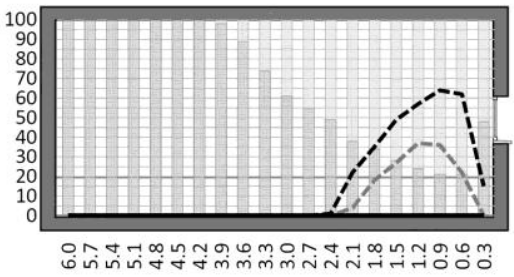

H.10.U.B

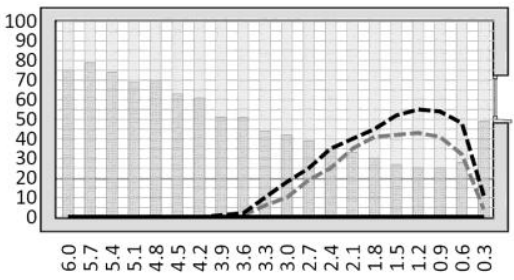

H.10.U.D

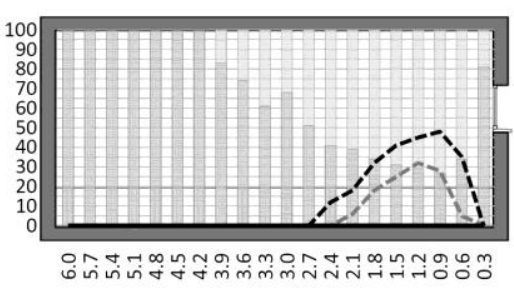

UDI $>2000$
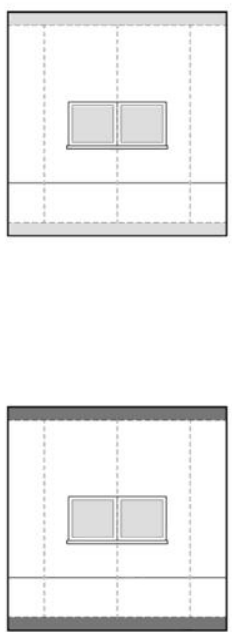

windows in the central axis, although they allow more illuminance in the side axis. As in the previous study, it is concluded that the illuminance in the back of the room tends to be homogenized.

As expected, and as is also the case with the previous study, the windows with greater surface allow higher daylight autonomy. However, in the case of horizontal windows there is no direct proportionality between the glazed area and the daylight autonomy produced, except at the study points near the back of the room.

\section{H. 20.C.B}
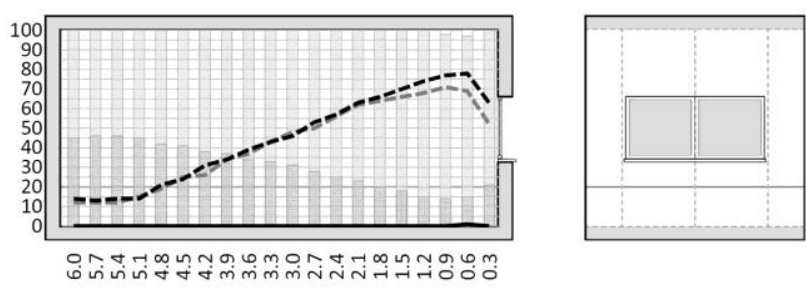

H.20.C.D
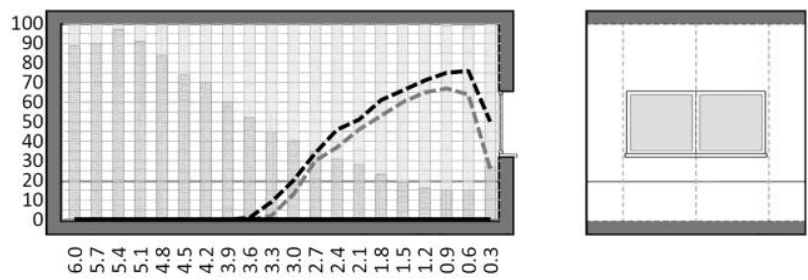

H.20.U.B
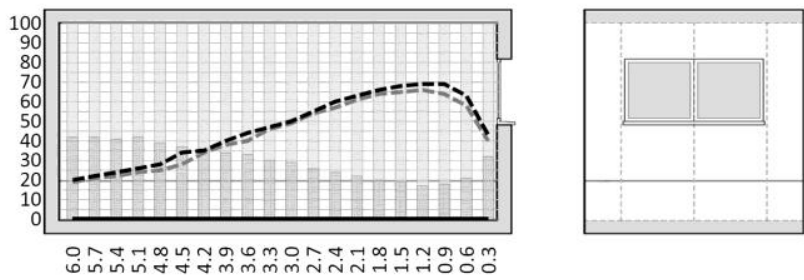

H.20.U.D
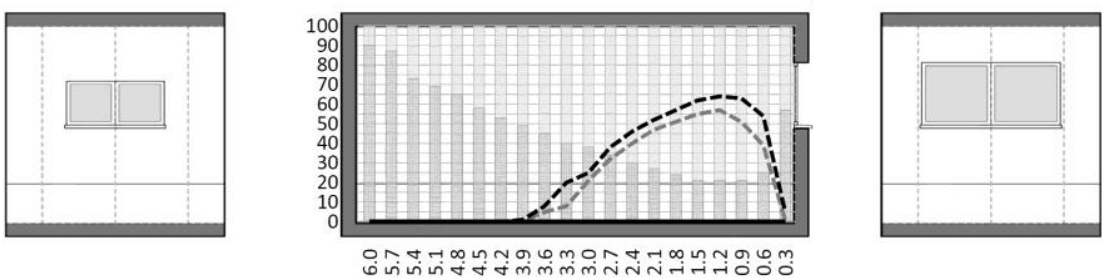

-DAmax

Fig. 4. Daylight autonomy and useful daylight illuminance for rooms with horizontal windows with surface between 10 and $20 \%$ of the façade.

Fig. 5 shows the daylight autonomy and useful daylight illuminance measured at the study points in rooms with vertical windows, under the conditions established in the methodology.

The vertical windows with a surface equal or higher than $30 \%$ of the façade are ignored in the calculation models because, according to the height/width ratio of the opening, they would be disproportionate to the façade.

The vertical windows in the upper position have also been ignored in this study, as the opening would be outside the façade.

A total of 4 calculation models with horizontal windows are considered, depending on the window surface and the reflectance of the inner surfaces of the room.

As can be deduced from Fig. 5, the daylight autonomy measured at the study points of the calculation models with vertical windows show a similar tendency to the analogous models with different window shapes. As expected, the 
daylight autonomy is higher near the window and lower at the back of the room.

According to calculation models with vertical windows, daylight autonomy measured at the side axis are considerably lower than those measured at the central axis, which implies that this window shape does not produce homogeneous light distribution.
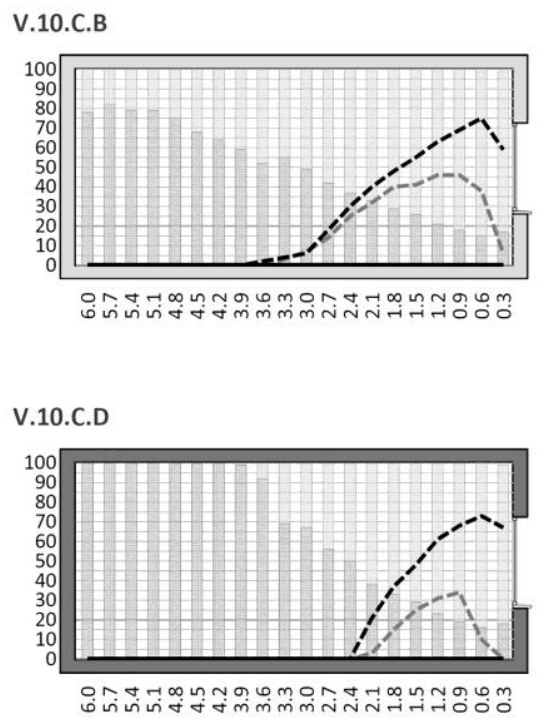

UDI $>2000$

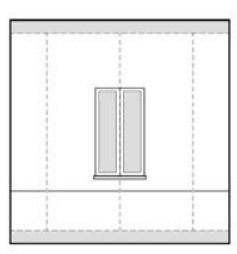

V.20.C.B

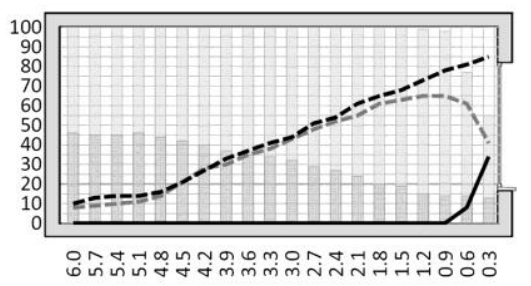

V.20.C.D

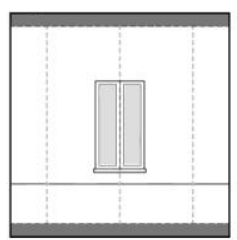

100
90
80
70
60
50
40
30
20
10

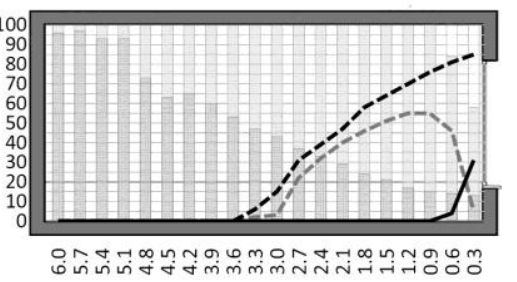

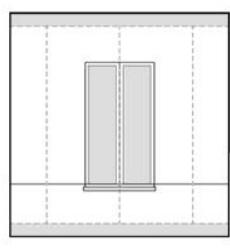

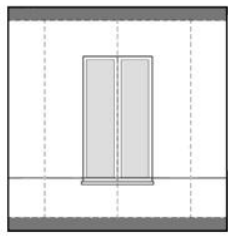

--.CENTER DAYLIGHT AUTONOMY

Fig. 5. Daylight autonomy and useful daylight illuminance for rooms with vertical windows with surface between 10 and $20 \%$ of the façade.

As follows from the ratio of the daylight autonomy measured at the central and side axes, it is confirmed that the light tends to be more homogeneous at the back of the room, regardless of window shape.

As noted in previous studies, the windows with greater surfaces allow higher daylight autonomy. However, the proportionality between the glazed area and the daylight autonomy is observed exclusively at the study points at the back of the room. It is also concluded that the variation of daylight autonomy produced by the reflectance of the inner surfaces of the room is higher at the back of the room and lower at the points next to the window.

\section{ANALYSIS OF RESUlTS}

After performing the trials and determining the quantification of daylight autonomy, an analysis of results of the model calculation is carried out under the conditions established in the methodology, according to the different variables.

\section{A. Analysis of Window Shape}

The first trial corresponds to the variation of the window shape, considering the reflectance of the inner surfaces of the room and the fact that the position of the openings is invariable.

The study sample for this analysis considers centered and upper windows with an area between 10 and $20 \%$ of the façade. A room with highly reflective surfaces is considered and the shape of the aperture is variable.

In order to establish conclusions based on this analysis, the relative difference of the daylight autonomy is calculated according to the window shape. This relative difference is calculated using the ratio of the daylight autonomy produced by horizontal or vertical windows and those obtained by square windows. The daylight autonomy evaluated corresponds to those measured at the central axis.

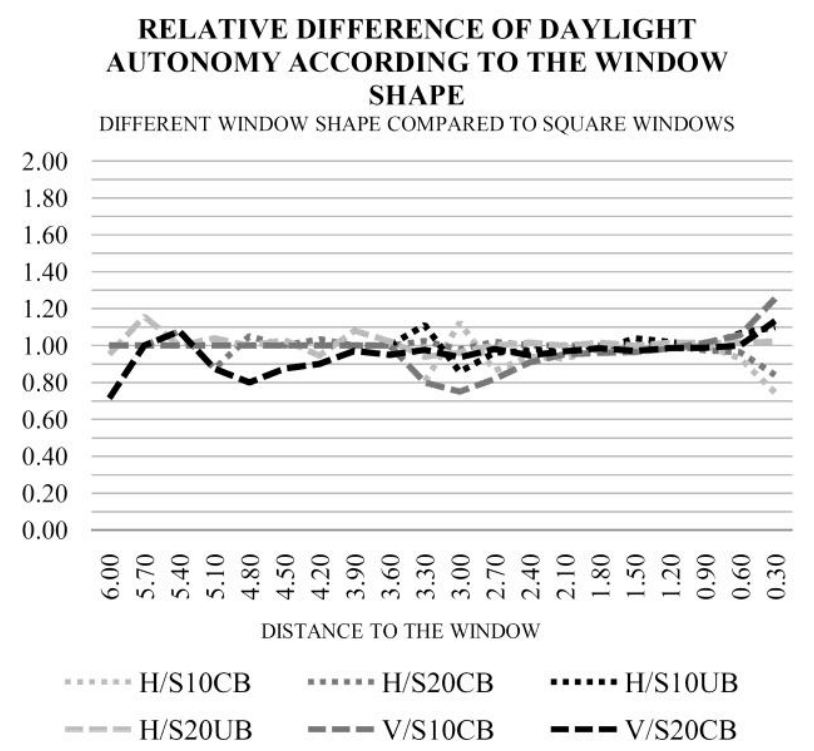

Fig. 6. Relative difference of daylight autonomy according to the window shape.

As can be concluded from Fig. 6, all the window shapes produce similar values of daylight autonomy. This means that the illuminance value in the central axis does not depend on the window shape. However, as can be observed in Fig. 5, the vertical windows produce less daylight autonomy in the side axis, therefore this shape is less effective in energy saving.

Moreover, as can be also concluded, the horizontal window produces similar values of daylight autonomy in the central axis. However, the values measured in the side axis is higher than those observed in other window shapes, so it can 
be concluded that the horizontal shape is more effective in energy saving than other shapes.

\section{B. Analysis of Window Size}

The second analysis studies the variation of the window size, considering that the shape and position of the openings and the reflectance of the inner surfaces of the room are invariable.

The study sample for this analysis considers centered square windows. A room with highly reflective surfaces is considered with the surface of the opening between 10 and $80 \%$ of the façade.

Just as with the analysis detailed above, the relative difference of the daylight autonomy is calculated according to window size. This relative difference is calculated using the ratio of the daylight autonomy produced by variable sized windows and those obtained by windows with areas equal to $20 \%$ of the façade. The daylight autonomy evaluated corresponds to those measured at the central axis.

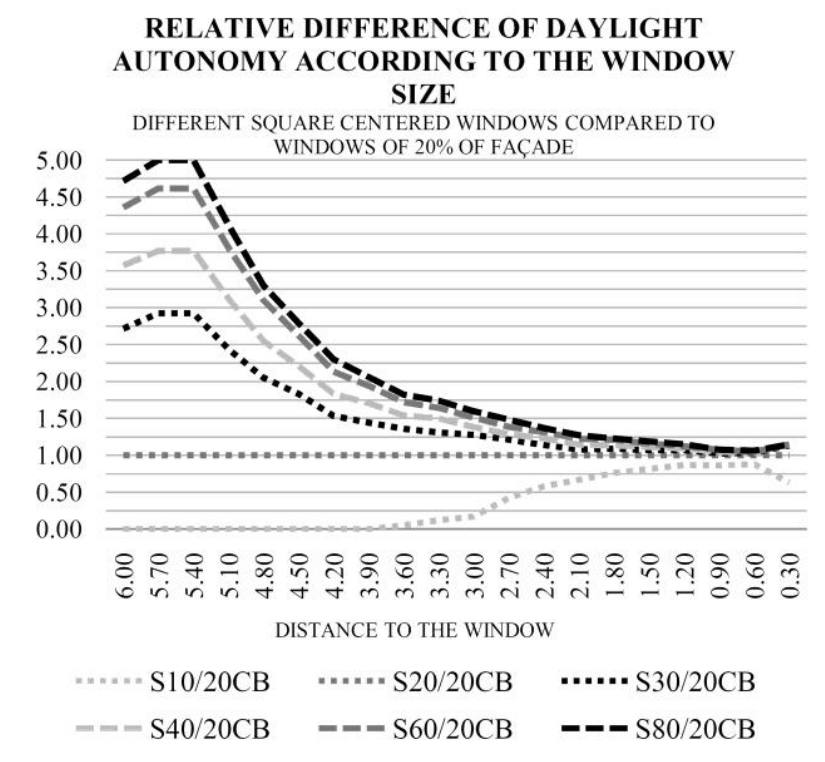

Fig. 7. Relative difference of daylight autonomy according to the window size.

As shown in Fig. 7, the daylight autonomy produced by variable sized openings is directly proportional to the glazed surface in the back of the room, from 5 to 6 meters. However, the daylight autonomy values tend to converge in the zone near the window. This behavior diverges from the measuring of daylight factors [9].

Therefore, it can be concluded that the window size is not relevant for energy saving in the zone near the façade. This conclusion is supported by the assumption that all window sizes studied in this research produce enough illuminance in the area close to the window. However, the window size is decisive in the back of the room, where the dependence on artificial lighting is higher than in the front.

\section{Analysis of Room Reflectance}

The last analysis studies the variation of daylight autonomy depending on the reflectance of the room, considering that the shape and position of the window are invariable.

The study sample for this analysis considers centered square windows with an area between 10 and $80 \%$ of the façade. The reflectance of the inner surfaces of the room is variable.

As in previous analyses, the relative difference of the daylight autonomy is calculated according to the reflectance of the inner surfaces of the room. This relative difference is calculated using the ratio of the daylight factors produced by low reflectance surfaces and those obtained by high reflectance surfaces. The daylight autonomy evaluated corresponds to those measured at the central axis.

As can be observed in Fig. 8, the relative difference of all values tends to converge to 1 in the zone between 0 and 1.50 meters, so it can be concluded that the reflectance of the inner surfaces of the room does not affect to the measurement of daylight autonomy in the zone near the window. However, the reflectance value is decisive in the back of the room, from 3.00 to 6.00 meters.

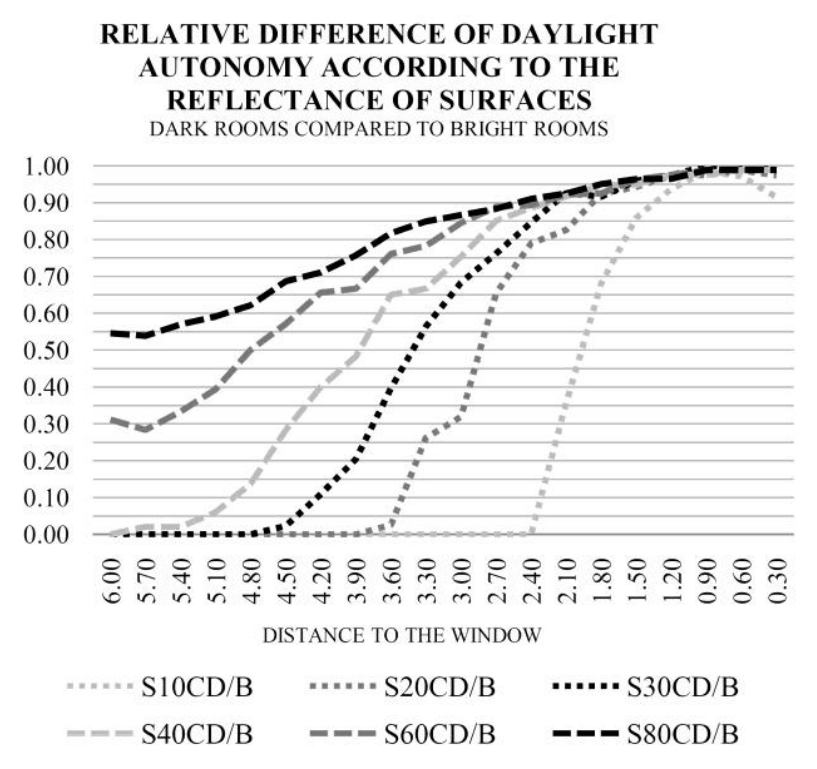

Fig. 8. Relative difference of daylight autonomy according to the reflectance of the inner surfaces of the room.

\section{CONCLUSIONS}

The analysis of results has assessed the variation of the daylight autonomy, which determines the energy saving in artificial lighting, depending on the shape, size and position of the opening, reaching several conclusions that can be applied to window design. Additionally, the study of the variation of the reflectance of the inner surfaces of the room allows determining the daylight autonomy based on this variable.

The quantification of the daylight autonomy serves as a basis for the analysis of results. However, it also offers a database of the natural illumination produced by a window within a room. Accordingly, the most representative calculation models of current architecture have been chosen for simulation, using the most common window designs. Obviously, this research does not cover all possible hypotheses, but aims to show the most frequent cases study under the most adverse sky conditions.

As can be concluded, all the window shapes produce similar values of daylight autonomy in the central axis. 
However, the vertical windows produce less daylight autonomy in the side axis, therefore this shape is less effective in energy saving. On the other hand, the values measured in the side axis for horizontal windows is higher than those observed in other window shapes, so it can be concluded that the horizontal shape is more effective in energy saving than other shapes.

Moreover, the daylight autonomy produced by variable sized openings is directly proportional to the glazed surface in the back of the room. However, the daylight autonomy values tend to converge in the zone near the window.

It is also concluded that the windows in the upper position allow higher luminance at the back of the room than those in centered locations.

Finally, it is also concluded that the reflectance value of the inner surfaces is decisive in measurement of daylight autonomy in the back of the room.

\section{REFERENCES}

[1] S. Treado, G. Gillette, and T. Kusuda, "Daylighting with windows, skylights, and clerestories," Energy and Buildings, vol. 6, 1984, pp. 319-330.

[2] D. H. W. Li, "A review of daylight illuminance determinations and energy implications," Applied Energy, vol. 87, 2010, pp. 2109-2118.

[3] I. Acosta, C. Munoz, M. A. Campano, and J. Navarro, "Analysis of daylight factors and energy saving allowed by windows under overcast sky conditions," Renewable Energy, vol. 77, 2015, pp. 194-207.

[4] H. H. Alzoubi and A. H. A. Zoubi, "Assessment of building façade performance in terms of daylighting and the associated energy consumption in architectural spaces: Vertical and horizontal shading devices for southern exposure facades," Energy Conversion and Management, vol. 51, 2010, pp. 1592-1599.

[5] CIE, "International lighting vocabulary," Commission Internationale de l'Éclairage, 2011.
[6] C. F. Reinhart, J. Mardaljevic, and Z. Rogers, "Dynamic daylight performance metrics for sustainable building design," Leukos, vol. 3 , no. 1, 2006, pp. 7-31.

[7] CIE, "Test cases to assess the accuracy of lighting computer programs," Commission Internationale de l'Éclairage, 2006.

[8] M. Maamari and N. F. Adra, "Application of the CIE test cases to assess the accuracy of lighting computer programs," Energy and Buildings, vol. 38, 2006, pp. 869-877.

[9] J. Ghisi and A. Tinker, "An ideal window area concept for energy efficient integration of daylight and artificial light in buildings," Building and Environment, vol. 40, 2005, pp. 51-61.

[10] D. H. W. Li, G. H. W. Cheung, and C. S. C. Lau, "A simplified procedure for determining indoor daylight illuminance using daylight coefficient concept," Building and Environment, vol. 41, 2006, pp. 578-589.

[11] P. Esquivias, C. Munoz, I. Acosta, D. Moreno, and J. Navarro, "Climate-based daylight analysis of fixed shading devices in an open-plan office," Lighting Research and Technology, 2015.

[12] C. M. Munoz, P. M. Esquivias, D. Moreno, I. Acosta, and J. Navarro, "Climate-based daylighting analysis in an open-plan office due to boundary conditions," Lighting Research and Technology, vol. 46, 2013, pp. 268-280

[13] C. F. Reinhart and P. F. Breton, "Experimental validation of Autodesk (r) 3Ds Max (r) Design 2009 and Daysim 3.0," pp. 7-35, 2009.

[14] U. S. Department of Energy, "EnergyPlus Energy Simulation Software".

[15] R. Perez, R. Seals, and J. Michalsky, "All-weather model for sky luminance distribution-Preliminary configuration and validation," Solar Energy, vol. 50, no. 3, 1993, pp. 235-245.

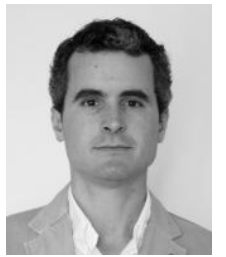

I. Acosta is a professor at the Department of Building Construction, University of Seville, Spain. He is a member of the research group TEP-130 which is focused on sustainability, energy efficiency, lighting and acoustics related to building design.

$\mathrm{He}$ belongs to the Instituto Universitario de Arquitectura y Ciencias de la Construcción. 